\title{
PROFISSÃO DOCENTE: CONTRIBUIÇÕES DA FORMAÇÃO CONTINUADA NO ESPAÇO DA ESCOLA
}

\author{
Célia de Fátima Rosa da Veiga \\ Gilberto Ferreira da Silva \\ Universidade La Salle/Canoas (LS) (Brasil)
}

\begin{abstract}
Resumo. Neste artigo se discute a importância da formação continuada e suas contribuições aos profissionais da educação em exercício, tendo em vista as modificações no ser e fazer pedagógico. No intuito de atender as necessidades que imperam em relação à formação docente no meio educacional e na sociedade, buscou-se dialogar com autores que abordam a formação continuada como um processo de capacitação ao profissional da educação, dentre os quais se destacam Freire (1997), Tardiff (2002) e Nóvoa (2007). Este estudo de cunho qualitativo é resultado de uma pesquisa que se amparou nos princípios metodológicos da pesquisa documental. Tomou por base empírica para a realização das análises o "parecer" produzido pelos professores que vivenciaram a formação continuada em uma escola de Educação Básica. A análise dos pareceres indicou, entre outros aspectos, que: a proposta de formação continuada do cotidiano, retratando o contexto escolar, com suas urgências, necessidades e projetos estimulam a dinamização e o aprimoramento das práticas da escola. Isso sugere a criação de espaços, nas reuniões regulares de formação, para tratar do que é rotina, seja com sucessos, seja com interferências que exigem maior atenção e diálogo. Outro aspecto diz respeito à formação centrada na escola, que acabou por produzir mudanças significativas na vida profissional e pessoal dos professores, dentre as quais destacamos o comprometimento com o processo educativo e a melhoria da qualificação das relações entre os profissionais no ambiente escolar.
\end{abstract}

Palavras-chave: Formação continuada, professores, qualificação das relações, formação em serviço.

\section{PROFESSION, TEACHER: CONTRIBUTIONS OF TEACHER TRAINING IN THE SCHOOL ENVIRONMENT}

\begin{abstract}
This article discusses the importance of teacher training and its contributions to professionals in education in face of the changes in the pedagogical way of being and doing. In order to meet the needs that prevail in teacher education, both in the educational environment and in society in general, we sought to dialogue with authors who approach teacher training as a process of improvement of the education professional like Freire (1997), Tardif (2002), and Nóvoa (2007). This qualitative study is the result of a research based on the methodological principles of documentary research. The empirical basis for conducting the analyzes was the "opinion" produced by the teachers who had undergone training in a (Elementary, Midle and High) school. The analysis of the opinions indicated, among other aspects, that: the proposal of continuous daily training portraying the school context with its urgencies needs and projects stimulate the dynamization and improvement of school practices. This suggests the need for creating spaces in regular training meetings to deal with the changing routine, either by looking at successes or interferences that require more attention and dialogue. Another aspect to emerge in the analysis concerns school-centered training that has led to significant changes in the professional and personal life of teachers. Among those we highlight the commitment to the educational process and the improvement of the qualification of the relations among professionals in the school environment.
\end{abstract}

Keywords: teacher training, teachers, qualification of relations, education in service. 


\title{
PROFESIÓN DOCENTE: CONTRIBUCIONES DE LA EDUCACIÓN CONTINÚA EN EL ESPACIO DE LA ESCUELA
}

\begin{abstract}
Resumen. En este artículo se discute la importancia de la formación continuada y sus aportaciones a los profesionales de la educación en ejercicio, teniendo en cuenta las modificaciones en el ser y hacer pedagógico. Con el fin de atender las necesidades que predominan en relación a la formación docente en el medio educativo y en la sociedad, se buscó dialogar con autores que abordan la formación continuada como un proceso de capacitación al profesional de la educación, entre los que destacan Freire (1997) ), Tardiff (2002) y Nóvoa (2007). Este estudio de cuño cualitativo es el resultado de una investigación que se amparó en los principios metodológicos de la investigación documental. Tomó como base empírica para la realización de los análisis del "parecer" producido por los profesores que vivenciaron la formación continuada en una escuela de educación básica. El análisis de los dictámenes indicó, entre otros aspectos que: la propuesta de formación continuada de lo cotidiano, retratando el contexto escolar, con sus urgencias, necesidades y proyectos estimulan la dinamización y perfeccionamiento de las prácticas de la escuela. Esto sugiere la creación de espacios, en las reuniones regulares de formación, para tratar de lo que es rutina, sea con éxitos, sean con interferencias que exigen mayor atención y diálogo. Otro aspecto se refiere a la formación centrada en la escuela que acabó por producir cambios significativos en la vida profesional y personal de los profesores, entre las cuales destacamos el compromiso con el proceso educativo y la mejora de la calificación de las relaciones entre los profesionales en el ambiente escolar.
\end{abstract}

Palabras clave: educación continuada, profesores, cualificación de las relaciones, formación en servicio.

\section{Introdução}

Vivemos um período ímpar na história humana. A evolução da ciência e das tecnologias, juntamente com o aumento da expectativa de vida, faz com que tenhamos grandes dificuldades de processarmos e organizarmos os saberes e os preceitos sociais, morais, educacionais, espirituais, entre outros. A diversidade cultural, agora mais presente em nosso cotidiano, faz com que o processo do ensino e da aprendizagem, obrigatoriamente, passe por um novo entendimento, impulsionando o possível professor a um processo constante de formação e de atualização.

A ideologia presente no que ensinamos e no que somos levados a ensinar faz do ato de educar um contrato de risco, no qual nos questionamos se educamos para a autonomia. Muitas vezes, as situações cotidianas nos tornam frágeis e impotentes frente aos desafios e colocam em dúvida a condição docente de favorecer o conhecimento necessário aos educandos.

A escola é um lugar de muitas possibilidades, é o espaço onde se pode construir e desconstruir sentidos para a mudança. Um dos desafios com que a escola se depara é o imenso volume de informações que se aglomera diante do espaço escolar; com isso, gera-se um aparente caos educacional, dificultando toda a ação educativa, principalmente para as escolas de Educação Básica. Frente à complexidade dos desafios diários, a escola vê-se, muitas vezes, perdida em seus princípios e sua missão, pois um novo discurso se faz presente no mundo atual: a não linearidade, a imprevisão e a complexidade, que exigem nova postura para sua compreensão (Machado, 2013).

O panorama de mudanças é tão veloz e diversificado que não se concebe mais uma oferta educacional pautada apenas pela formação inicial e/ou acumulada dos docentes (Moriconi, 2017). A mudança, no sentido esperado para a educação, exige e 
apoia-se na formação contínua e, portanto, na atualização dos recursos humanos disponíveis, ou seja, na capacitação permanente dos professores em serviço.

$\mathrm{O}$ artigo tem o objetivo de analisar quais as contribuições da formação continuada ao professor em serviço, tendo em vista as modificações no ser e fazer pedagógico. O estudo é resultado de uma pesquisa finalizada, desenvolvida a partir da escola compreendida como lugar de possibilidades, da formação como espaço de significação da vida e da formação continuada como um convite à qualificação do ser e fazer pedagógico.

Ao mesmo tempo, vivemos num contexto de medo e busca de segurança em qualquer lugar da sociedade, pois esta cria suspeitos, estranhos estrangeiros, ameaças ao convívio nos espaços públicos, sendo a escola um deles. Porém, se esse é um problema que a globalização tornou mais evidente, esta pode ser um componente da solução, por outro lado, já que a comunicação entre diversos tipos urbanos e culturais pode ser, seguramente, um passo para a solução da intransigência coletiva e da intolerância individual (Silva, Cabrera, 2013; Bauman, 2007).

Nesse cenário de fragilidade está inserida a escola. Convivemos todos com a cultura de consumo que criou um cenário propício para a deflagração de ofertas em um mercado de produtos que se quer inesgotável. Os professores, nesse contexto, convivem com a dificuldade de educar na "síndrome consumista" em que a infância é passível de sondagem e engendramento de desejos e satisfação. O desafio é educar adolescentes e crianças que são impulsionados a consumir e que influenciam nas decisões dos pais no momento da aquisição de algum produto. Bauman (2007) trabalha a visão da educação como "mercado", a relação entre ignorância, escolha e política e a necessidade de buscarmos a oportunidade de escolher segundo a nossa própria condição e dentro da nossa possibilidade.

Utilizando o termo de Hannah Arendt, o autor alerta que vivemos "tempos de obscuridade", de busca, proporcionando um diálogo com os pensamentos do filósofo Theodor W. Adorno, na compreensão da dimensão dessa sociedade líquida que solapa a verdade e sustenta o status quo. Este se apoderou do conhecimento, tornando-o um valor de mercado, e fomentou a globalização unilateral, desumana, que pouca importância dá às chamadas "vítimas colaterais" desse processo galopante.

Nessa dinâmica de reflexão, Nóvoa (2004) salienta que a profissão docente vive uma desorientação global, uma crise que vem se arrastando e que, em grandes medidas, tem relação com o perder de referências fundamentais do que era o grande projeto de escolarização em termos sociais mais amplos, quando os professores eram os grandes protagonistas desse projeto. $\mathrm{O}$ autor coloca que o projeto de escolarização vive hoje um momento de grandes dúvidas, em termos históricos, e ressalta que a profissão docente tem sentido a ausência de qualificação, sabendo que esta é uma das finalidades da escola e da educação.

Novamente, Bauman (2007) nos faz ponderar sobre a possibilidade de perceber esse mundo líquido que nos atinge, nos molda, mas que não nos domina por inteiro. Neste ponto de resistência pode estar contida a ferramenta para a apreciação e remodelação dessa globalização, que gera tantos males quanto alguns benefícios. Basta observar com olhar mais crítico o presente e imaginar que futuro pretendemos para nós, para a escola, e para a humanidade que representamos.

Diante desse contexto, fica o desafio do que a escola faz para reverter esse quadro, pois o docente está impregnado por essa cultura de complexidades, avanços 
científicos e tecnológicos, conflitos de relações e a desvalorização da profissão. Uma possibilidade de transformação desse mal-estar vem por meio da formação continuada, oferecida aos profissionais da educação para que possam impulsionar suas atividades em possibilidades de crescimento pessoal e profissional.

Nesse sentido, Nóvoa (2007) aborda a questão do social e do educativo, destacando que são os próprios professores quem têm de encontrar os caminhos, as soluções e assumir as decisões. Isso está dentro do quadro da autonomia da profissão docente e, por isso, destaca que a única maneira de estar na educação é numa perspectiva constante de interrogação, de dúvida, de procura dos melhores caminhos em cada momento.

Nóvoa (2007) também ressalta que é importante que as escolas passem a consagrar algum tempo àquilo que os homens das sociologias designam por " "tarefas de concepção e de inovação", ou seja, o trabalho de pensar o trabalho. Quando isso não acontece, outros assumem essa tarefa.

$\mathrm{Na}$ educação, grande parte dos profissionais perdeu a capacidade de priorizar um pensamento transformador. Mais do que nunca, necessita-se de intelectuais transformadores, de produtores de ideias autônomas, que busquem fortalecimento no corporativo, nos seus pares, nas escolas, e invistam em profundidade no trabalho intelectual transformador a partir da realidade educacional concreta. Para que isso aconteça, a formação no espaço escolar precisa ter sentido, significado para a vida (Silva e Machado, 2018).

Em nossos dias, mais do que nunca se faz necessário refletir sobre o nosso ser e estar no mundo. São importantes o olhar atento ao trabalho diário e a análise da prática em relação ao significado para a atuação profissional. $\mathrm{Na}$ escola e dentro da sala de aula, percebem-se muitos desafios. Muitos deles são trazidos pelos alunos a partir de seu mundo quotidiano, como inquietudes constantes, conflitos familiares, estranhamento frente aos professores, entre tantos outros. Todos esses fatores entrelaçam-se nas relações escolares. São alunos espertos, às vezes confusos, com grande potencial de aprendizado, mas que são pouco desafiados para despertar as habilidades que possuem, principalmente as potencialidades que envolvem relações de convivência. Nisso tudo, nota-se falta de qualificação ao profissional da educação para que, em conjunto com os demais professores, possa descobrir novas práticas, embasado numa teoria que fundamente a ação pedagógica diária.

Nesse sentido, o aprimoramento contínuo não supõe apenas enriquecimento cultural, mas constitui uma necessidade para poder fazer frente aos novos desafios que o trabalho diário impõe ao docente. Portanto, à medida que o professor reflete sobre seu fazer pedagógico no contexto local e global, surge a necessidade de fundamentar teoricamente sua prática mediante estudos significativos e permanentes a respeito de si e do mundo em que se insere (Silva e Cabrera, 2013).

Quanto a isso, Freire (1984) nos diz que estudar e ler sobre a prática não é apenas mentalizar letras. Para ser professor é fundamental ter leitura de mundo, e esta precede a leitura da palavra, uma está conectada com a outra para a continuidade da leitura da vida. $\mathrm{O}$ autor afirma ainda que "[a] linguagem e a realidade se prendem dinamicamente. A compreensão do texto a ser alcançada por sua leitura crítica implica percepção das relações entre o texto e o contexto." (Freire, 1984, p. 11).

Nessa linha de pensamento, podemos supor que, quando um professor não lê além do que faz e também não consegue significar o sentido da leitura como uma 
releitura da vida, sua função fica esvaziada. Portanto, esse é mais um argumento que justifica a necessidade de uma proposta de formação continuada que tenha significado, que transcenda o óbvio, tanto para o professor quanto para o aluno.

Freire (1984) sustenta ainda que não é possível uma aprendizagem de uma via só, ou mera transmissão dos saberes carregados pela experiência do professor. Ele salienta que o diálogo e a conscientização são aspetos fundamentais no processo de interação entre professor e aluno, pois a educação acontece num ato de troca mútua entre os saberes, no relacionamento entre professor e aluno, num ato de valorização dos conhecimentos de ambos os lados.

No entanto, para que ocorra um verdadeiro saber que promova o humano, é preciso reconhecer que aprendizagem se faz na relação de alegria e esperança entre professor e aluno. Esperança de que ambos podem aprender, ensinar, produzir e juntos inquietar-se num movimento de busca constante de sentido e significado frente à atividade educativa em que estão envolvidos (Freire, 2007).

Nessa dinâmica de vida, talvez, esse seja o caminho para fazer o professor perceber o aluno como sujeito do seu processo. Sabemos que é a passos lentos que encontramos a maneira mais viável para a realização de tal utopia. Para isso, a visão educativa deve ser articulada coerentemente. Aliás, essa é uma forma de ressignificar os princípios da educação que começam desde muito cedo na vida do ser humano e conquistar formas de superar as fragilidades da vida através do resgate dos laços humanos e da autonomia do professor.

Partindo desse movimento, precisamos resgatar o caráter do convívio sadio docente. Faz-se necessária abertura e vontade para que isso se faça realidade na vida escolar. E, como nos afirma Freire (1997), a abertura e o cuidado com o aluno, o querer bem, não significa uma relação de infantilização ao aluno, mas de comprometimento com o ensino e a educação que ele está recebendo. Significa que a afetividade é algo saudável e não deve assustar o professor, nem inibi-lo de expressá-la, mas, "significa que esta abertura ao querer bem é a maneira que tenho de autenticamente selar o meu compromisso com os educandos, numa prática específica do ser humano." (Freire, 1997, p. 159).

Ainda para o mesmo autor (1997, p. 161), a "afetividade não se acha excluída da cognoscibilidade. O que não posso obviamente permitir é que minha afetividade interfira no cumprimento ético de meu dever de professor, no exercício de minha autoridade." Por outro lado, o pouco caso à aprendizagem e ao crescimento ético e moral do aluno fere todos os envolvidos nesse processo, alunos, professores, pais e a comunidade educativa. Interfere, também, na sensibilidade e na abertura à mudança da prática educativa e na disposição necessária do fazer do docente. Nesse sentido, "a prática educativa é tudo isso: afetividade, alegria, capacidade científica, domínio técnico e serviço da mudança, ou lamentavelmente, da permanência do hoje." (Freire, 1997, p. 161). Dessa forma, entende-se que é preciso, mais do que nunca, primar por uma proposta organizada de formação continuada ao profissional em exercício, que contemple aspectos filosóficos, sociológicos, epistemológicos e humanos do professor, pois essa formação servirá de ferramenta indispensável para o sucesso do ato pedagógico.

Não se pode conceber o processo educacional, na era da informação e das interrelações, de forma fragmentada, o que resultaria no fracasso e na frustração, tanto dos alunos quanto dos professores. As mudanças pelas quais passam o mundo e a sociedade 
nos levam a entender que é preciso considerar as inter-relações e as conexões da vida para transcender-se como sujeito em todas as dimensões.

Foi-se a época em que vivíamos um paradigma de uma verdade científica, marcada pela objetividade, contrapondo-se ao sujeito, em si. $\mathrm{Na}$ atualidade, sujeito e objeto, dois mundos que caminham juntos, têm no seu interior reflexivas categorias que passam desde o conhecimento até a sensibilidade, o sonho e a esperança (Grinspun e Azevedo, 2006). Nesse movimento único, encontra-se a necessidade de qualificar as relações do ser e do fazer do professor em exercício (Vaillant, 2016).

\section{Sobre o método: olhares sobre a formação continuada}

Ao analisar a visão dos profissionais da educação sobre a formação continuada na escola, procura-se mostrar primeiro, uma síntese do cenário no qual os sujeitos participantes constroem-se como pessoas e profissionais. Para isso, são trazidas as falas dos professores que participaram das reuniões de formação continuada em uma escola do centro do Rio Grande do Sul. A escola está localizada na região central do estado, a $290 \mathrm{~km}$ da capital Porto Alegre. É uma instituição privada com 1.458 alunos e um corpo funcional de 98 professores, sendo 11 mestres, 32 especialistas e 55 graduados.

A formação continuada no colégio foi reestruturada, desde o ano de 2010 , de modo a atender duas frentes de formação: uma, individualizada, para acompanhamento e atendimento das singularidades de cada educador; outra, de estudo e aprofundamento coletivo, envolvendo simultaneamente todos os educadores. Dentre os vários objetivos da formação continuada oferecida pelo colégio, destacam-se: refletir sobre a prática pedagógica, estabelecendo relações entre a teoria e o fazer docente; socializar ideias e experiências significativas; proporcionar momentos de aprofundamento teórico por meio de leituras, palestras, seminários, entre outros, sobre temas relevantes à prática pedagógica; refletir sobre a prática pedagógica, estabelecendo relações entre a teoria e o fazer docente; socializar ideias e experiências significativas; ressignificar as ações docentes, desafiando a implementação dos estudos realizados; planejar ações inovadoras; manter os professores em constante avaliação do seu trabalho, em busca da realização de melhorias; e aprofundar a fundamentação franciscana e incentivar o processo de melhoria contínua na escola, pela elaboração de planos de ação, tendo como base a autoavaliação docente.

A modalidade da formação escolhida pela escola foi de: a) Assessoramento individual ao professor de três horas, uma hora/mês, sendo que os profissionais agendam com a coordenadora pedagógica o seu encontro de uma hora para realizar a sua autoavaliação dirigida/assessoramento. A metodologia para o assessoramento conta com uma ficha/roteiro da autoavaliação, que orientará o encontro do professor com a coordenadora pedagógica. b) Reuniões de estudo num total de 16 horas, quatro horas/mês. A metodologia é com leituras prévias em preparação da reunião, seminários de socialização, atividades práticas, vivências e oficinas. Além disso, é destinada uma hora de cada encontro para a reunião setorial. c) Reunião de planejamento série/setor num total de quatro horas/série, uma hora/mês. A metodologia de trabalho adotada foi de viabilizar um encontro por série para planejamento, análise de desempenho, resultados e casos especiais. As professoras da Educação Infantil ao $3^{\circ}$ ano do Ensino Fundamental realizam planejamento semanal de duas horas, totalizando aproximadamente, 96 horas ao ano. 
As reuniões pedagógicas realizadas a cada início de ano totalizam 40 horas, oito horas/dia. Em 2013, aconteceram nos dias 2, 3 e 4 de janeiro, e 7 e 8 de fevereiro. As reuniões foram intercaladas entre estudo e planejamento. Ao término de cada reunião de formação continuada, é aplicado um instrumento avaliativo, individual, no qual ficam registradas as percepções, opiniões e sugestões dos professores quanto ao tema, ao conteúdo, à metodologia, à abordagem e ao tempo da reunião. Esse instrumento serve como objeto de reflexão do grupo coordenador da formação continuada no momento de planejar a reunião subsequente. São algumas dessas avaliações/contribuições que serão analisadas, procurando destacar a contribuição ou não da formação continuada centrada na escola.

\section{Resultado e discussões}

Mais do que nunca, trabalhar atualmente na educação e por ela é um convite para estar sempre em aprimoramento. Sabemos que um professor que arrisca continuar trabalhando em educação sem ter presente a sua função de estudar permanentemente sempre incorre numa situação de fragilidade da profissão. Qualificar os saberes que traz da experiência profissional é um desafio indiscutivelmente presente na carreira docente.

Ao abordar as principais características do saber experiencial dos professores, Tardif (2002) destaca a importância do saber experiencial ligado às funções dos professores. Ele salienta que é um saber prático, interativo, plural, heterogêneo, complexo, evolutivo e dinâmico, que se transforma e se constrói no âmbito de uma carreira, de uma história de vida profissional, e implica uma socialização e uma aprendizagem da profissão. É um saber social, construído pelo ator em interação com diversas fontes sociais de conhecimentos, de competências, de saber-ensinar provenientes da cultura, da organização escolar, dos atores educativos, das universidades, entre outros.

Durante a concretização da formação continuada, conduzida pela equipe da escola, muitas foram as descobertas no processo de aprimoramento pessoal dos professores, tendo estas se destacado nas falas dos participantes. As contribuições dos professores por meio de suas falas retratam qual a dinâmica que acrescenta conhecimento e credibilidade à sua função de profissionais da educação. É o que comenta a professora de educação física, situada como P1 nesta pesquisa. Ela foi uma das participantes da formação continuada, oferecida aos professores na escola.

Quero ressaltar a importância dos temas das oficinas e a forma como foi desenvolvido o processo formativo. Começando que podemos escolher o tema que gostaríamos de assistir e com isso houve envolvimento muito grande por parte dos participantes. A oficina que participei foi bem trabalhada e o assunto bem abordado (P1).

A densidade da atividade na vida do professor estabelece conexão dos participantes, proporcionando interesses pedagógicos, escolhas com autonomia, interação dos pares e reflexão. Com isso, podem elaborar melhor seus planejamentos, projetos individuais e coletivos, suas aulas, as estratégias pedagógicas para o ensino e a aprendizagem, bem como fornecer pistas para o aperfeiçoamento da formação continuada oferecida pela escola durante o ano escolar. 
Diante do exposto, a contribuição que Nóvoa (2010) apresenta ressalta que é preciso nos adequarmos às novas ideias, políticas e práticas para realizar uma melhor formação continuada de professores. Ao tratar da necessidade de buscar novas perspectivas, salienta que a ideia central vai além da intenção de atualizar, abrange "potencializar uma formação que seja capaz de estabelecer espaços de reflexão e participação, para que os professores 'aprendam' com a reflexão e a análise das situações problemáticas... e para que partam das necessidades democráticas, sentidas, do coletivo." (Nóvoa, 2010, p. 42). A professora de língua inglesa do $5^{\circ}$ ano do Ensino Fundamental (P2) retrata:

As oficinas temáticas sobre a juventude foram muito significativas para o grupo. A presença dos alunos, a preparação em parceria com os professores e os ex-alunos foram de grande aprendizado para todos. Parabenizo a todos os coordenadores das oficinas pelo belo trabalho. Cito também, o estudo de retomada dos referenciais do PPP, muito rico no estudo, aprofundamento e socialização das ideias e do conteúdo (P2).

Nesse espaço de formação, imbricados estão todos os envolvidos no processo educativo: alunos, professores e demais participantes ocultos e não ocultos. Foi uma alternativa de trabalho colaborativo, com a intenção de promover um novo processo formador que possibilitou o estudo aprofundado do documento que embasa a proposta pedagógica da escola, no caso o Projeto Político Pedagógico (PPP), citado pela professora. Este favoreceu a socialização das ideias para o surgimento de novos elementos possíveis de mudanças, a serem inseridos nas políticas e nas práticas de formação.

Nesse sentido, perceber os desafios implicados na ação educativa atual é o primeiro passo para a justificativa da relevância e da necessidade da formação continuada. Se o professor não for livre e capacitado, o seu trabalho vai resultar numa mera repetição ou indução ao determinado, fazendo do agir e pensar educativo um instrumento a serviço da falta de liberdade e autonomia para si próprio e para seus alunos.

Para que isso não aconteça, o professor deve atentar não apenas ao que faz em sala de aula, mas nas implicações do que é ser professor numa época em que está latente a busca por uma educação que tenha significado para a vida do aluno, consciente de questões do cotidiano que afetam a realidade da comunidade local e global nas suas várias dimensões.

A busca pela compreensão do professor como pessoa e profissional é um desafio constante para todos os envolvidos no processo formativo. Nesse contexto, a professora do $1^{\circ}$ ano do Ensino Fundamental comenta: "a oficina 'o jovem e a espiritualidade' foi ótima inclusive destaco a participação dos alunos e ex-alunos, de jovens que atuam em grupos de jovens ou fazem trabalhos voluntários. Também considero importante o estudo mais sistemático do PPP, que é nosso instrumento de trabalho" (P3). Desse modo, Nóvoa (1999, p. 16) argumenta que "a natureza do saber pedagógico e a relação dos professores ao saber, constituem um capítulo central da história da profissão docente." Com isso, o professor vai constituindo-se autônomo em sua trajetória, para que a sua docência também seja portadora de identidade pessoal. Ou seja, é necessário ter em mente uma perspectiva subjetiva, que o torne ímpar em suas ações pedagógicas e um constante aprendiz em seus saberes. É isso que comenta a professora de redação do Ensino Médio: 
Gostaria de registrar meus parabéns pela dinâmica da oficina "O jovem e a escolha profissional", pois houve o momento de interiorização, de contribuição com os depoimentos dos jovens e de integração do grupo, todos muito enriquecedores. A dinâmica do SOE também foi ótima, proporcionando a troca com os colegas de vários setores $(\mathrm{P} 4)$.

Já a professora de matemática do $4^{\circ}$ ano do Ensino Fundamental expressou: "Maior tempo de encontro com todos os professores do $4^{\circ}$ ano para a descrição do projeto interdisciplinar" (P5). Nóvoa (1999) explica que a identidade que o professor carrega traz as marcas da sua atividade. Com o passar do tempo, ela vai se tornando seus próprios olhos, e aos olhos dos outros revela sua cultura, seu ethos, suas ideias, suas funções, seus interesses e, com isso, modifica também, o seu "saber trabalhar".

Todo esforço do educador em cultivar-se e, da sua consciência diante da complexidade da educação, suas interfaces e implicâncias, faz com que a escola, num processo dinâmico, possa discutir, pensar e agir de forma diferente, tanto no administrar uma sala de aula, uma turma, um conteúdo, uma proposta, um projeto, como diante do compromisso que tem com a própria vida.

O professor de história do Ensino Médio fez a sua avaliação, dizendo: “Acredito que a distribuição do tempo, priorizando os encontros setoriais e por série/ano foi bem melhor esse ano. No entanto, poderíamos ter mais tempo para que os professores também tivessem a oportunidade de socializarem em seus componentes curriculares comuns" (P6).

Frente a isso, Tardif (2002) menciona as relações entre tempo, trabalho e aprendizagem dos saberes profissionais dos professores de profissão que atuam no ensino primário e secundário, isto é, dos saberem mobilizados e empregados na prática cotidiana. Esses saberes servem para resolver os problemas dos professores em exercício, dando sentido às situações de trabalho que lhes são próprias. Ressalta que os saberes profissionais dos professores são plurais e temporais, uma vez que são adquiridos no contexto de uma história de vida e de uma carreira profissional, "pois trazem à tona, no próprio exercício do trabalho, conhecimentos e manifestações do saber fazer e do saber ser bastante diversificados e provenientes de fontes variadas, das quais podemos supor, também que sejam de natureza diferente." (Tardif, 2002, p. 61). Desse modo, ensinar supõe aprender a ensinar, aprender progressivamente os saberes necessários à realização do trabalho docente através da experiência profissional e pessoal do professor.

Tardif (2002) aborda também o ato de trabalhar, em termos sociológicos, explicando que o trabalho modifica a identidade do trabalhador, pois trabalhar não é somente fazer alguma coisa, mas fazer alguma coisa de si mesmo, consigo mesmo.

Daí a necessidade da formação continuada dos professores no processo humanoprofissional de crescer sempre. Freire (1997, p. 103) continua afirmando que "o professor que não leve a sério sua formação, que não estude que não se esforce para estar à altura de sua tarefa não tem força moral para coordenar as atividades de uma classe... a incompetência profissional desqualifica a autoridade do professor."

Toda e qualquer mudança social, familiar, econômica, política carece passar primeiro por um processo de mudança de mentalidade. Algo próprio da alma, da racionalidade. A transcendência para uma forma nova sem perder a identidade própria ou subjugar a do interlocutor deve ter seu sustento nos momentos de autoformação desejados e sustentados pela vontade do próprio educador, como também da vontade 
política das instituições educacionais em qualquer esfera de poder. Para quem está chegando na escola, a visão é outra.

Como estou chegando na escola tudo é muito novo para mim. Participar da semana pedagógica contribuiu para o meu amadurecimento como profissional, além de possibilitar um momento de reflexão em busca da essência do professor e a importância do seu papel na construção do conhecimento dos educandos (P7).

Nessa perspectiva, Tardif (2002) aponta fontes de aprendizagens nesse início de carreira. A primeira vem acompanhada por uma fase crítica, em que, a partir das certezas e dos condicionamentos da experiência prática, os professores julgam sua formação anterior. A outra aprendizagem do trabalho é a experiência dos outros, dos pares, dos colegas. Importa o que ele aprende sozinho em sua atividade e o que ele aprende com seus colegas de profissão durante sua carreira.

Nas instituições de ensino de qualquer processo educativo, o professor é convidado a primar pelo compromisso individual e social de transformação da realidade com postura ética diante do educando. Nesse processo, "não podemos nos colocar na posição do ser superior que ensina um grupo de ignorantes, mas sim na posição humilde daquele que comunica um saber relativo a outros que possuem outro saber relativo." (Freire, 1979. p. 29). É uma relação de reciprocidade de saberes, de conhecimentos, que vai construindo o professor ao longo do processo educativo.

A fala do professor de educação física segue esse caminho, quando ele fala da dinâmica realizada pelo Serviço de Orientação Educacional (SOE), visando a integração dos professores, pois considerou o conhecimento do grupo importante para a convivência e a unidade de trabalho. Ele expressa: "Bastante positiva a atividade realizada na $1^{\text {a }}$ hora da tarde do dia 04/01, onde conhecemos um pouco mais de nossos colegas aumentando nossa socialização e unificando o grupo" (P8). A relação entre os pares para fluir o trabalho coletivo e colaborativo faz-se essencial nesse processo. São indivíduos em busca de um mesmo propósito, o ensino e a aprendizagem, o desenvolvimento de competências, habilidades e atitudes dos estudantes. Todos aqueles que trabalham com educação passam por processos de aprendizado do respeito, do confronto, das estratégias acertadas para construírem alternativas, em conjunto. Eles constituem um coletivo que trabalha com pessoas em formação, criando neles um espírito transformador e, consequentemente, isso agrega à instituição escolar disposição para realizar mudanças significativas em seu contexto.

Esse dispor-se para a mudança passa pelo ser e pelo fazer, ou seja, envolve o subjetivo do ser professor. Tardif (2002) considera a dimensão subjetiva da carreira remetendo ao caso de que os indivíduos dão sentidos à sua vida profissional e se entregam a ela como atores cujas ações e projetos contribuem para definir e construir sua carreira. A professora da Educação Infantil também avaliou a experiência de forma positiva. Ela comenta que é necessário "[c]ontinuar com atividades envolvendo dinâmicas, pois ajuda na integração com os colegas" (P9). Isso revela que a professora considera positivo criar uma cultura de colaboração no trabalho escolar. "Para promover a cultura colaborativa, as instituições educacionais deveriam assumir o risco da inovação, reivindicar tempo e espaço para uma formação na instituição" (Inbernón, 2010, p.70).

Com as explanações dos professores, vê-se o espaço positivo da formação continuada na escola, na promoção da reflexão dos professores, potencializando um processo constante de autoavaliação sobre o que se faz e para que se faz na educação. 
Nesse processo, buscou-se compreender melhor o que vivem os professores e seus pares e, desse modo, levá-los a melhor compreenderem a si mesmos, na singularidade e no pertencimento ao trabalho educativo. Nessa mesma dinâmica, Tardif $(2011$, p. 7) coloca que é importante, "no plano intelectual, um processo de descoberta mútua e de aprendizagem coletiva, através do compartilhamento de experiências e situações profissionais variadas, mas que têm ressonâncias comuns".

Diante do exposto pelos professores em seus escritos, percebe-se a contribuição da formação continuada, mostrando que ela produziu mudanças significativas na vida profissional e pessoal desses profissionais, como também mostrou a possibilidade de qualificar as relações no ser e no fazer pedagógico diário.

\section{Considerações finais}

A formação acarreta muitos benefícios para todos os que se envolvem inteiros na educação. Nesse sentido, a formação oferecida ao professor torna-se atitude de conscientização, pois busca construir novos saberes, a partir das vivências relacionais que acontecem nos espaços escolares, na perspectiva de construir uma ação recíproca entre professor, aluno, pais, conteúdos, projetos, comunidade educativa. Enfim, uma escola que considera o entrelaçamento da vida como um processo permanente de mudança é identificada como um espaço de interação e cooperação.

Ao considerar, também, a individualidade e diversidade do professor, seu jeito de ser e fazer, há um movimento de valorização de sua profissão e de sua autonomia, implicadas no compromisso com a coletividade. Nesse comprometimento, uma das oportunidades é desenvolver uma proposta de formação de professores na qual se considere a oportunidade de criar situações de relação, em que o professor desenvolve a capacidade de criar vínculos de confiança com seus pares. Nesse intuito, ambos, escola e professor, traçam estratégias de ensino e aprendizagem com autonomia, respeito e compromisso de reciprocidade coletiva na construção de uma educação comprometida com o desenvolvimento social da vida e do contexto de atuação.

Outro aspecto revelador da pesquisa é a proposta da formação continuada do cotidiano, retratando o contexto escolar, com suas urgências, necessidades e propostas, para a dinamização e o aprimoramento dos projetos da escola. Isso sugere a criação de espaços, nas reuniões regulares de formação, para tratar do que é rotina, seja com sucessos, seja com interferências que exigem maior atenção e diálogo. Os resultados positivos também devem ser tratados, a fim de se potencializar para a excelência do trabalho realizado na escola. E o que é necessário cuidar com atenção, procurar fazer o movimento do planejamento de ações proativas a serem discutidas e dinamizadas para a visualização da comunidade educativa. Nesse processo, o ciclo de uma proposta de pesquisa participativa contribui para efetivar experiências positivas do que pode acontecer na escola, num processo contínuo e dinâmico, gerando a transformação do contexto escolar e das pessoas que nela atuam diariamente.

Para introduzir uma cultura colaborativa entre os professores e a escola, mediante a formação continuada, faz-se necessário romper com o personalismo e o individualismo pedagógico. E isso exige tempo e paciência, pois precisa-se criar momentos, dinâmicas e consciência do que pode ser mudado. Com isso, a escola estará potencializando a estima coletiva dos docentes para a resolução de problemáticas, seja do ensino, seja sociais. Nessa relação entre escola e sociedade, muitas vezes a escola 
reproduz o que acontece fora dela, e o que se busca é criar estratégias para a compreensão das novas estruturas familiares, sociais e educacionais. Nessa construção e no desenvolvimento de novos jeitos organizativos na escola, tem-se a perspectiva do desenvolvimento pedagógico e de gestão, numa dinâmica de parceria e crescimento de todos os envolvidos no processo.

O desafio que se impõe é a densidade das experiências e das práticas de formação continuada oferecida ao professor. Estas podem trazer autenticidade científica. A busca pela compreensão do professor como pessoa e profissional é um desafio constante para todos os envolvidos no processo formativo. O esforço pela dinamização de conteúdos significativos, de outro lado, impulsiona uma organização no currículo escolar, no pensar a escola como instituição séria que apresenta conhecimentos para a vida toda. Tudo isso envolve uma proposta de mudança do processo formativo, de ensino e aprendizagem, bem como na dinâmica pessoal e profissional do professor que procura por aperfeiçoamento constante em seu fazer e ser pedagógico. É uma fonte de reflexão que convida ao aprofundamento e comprometimento com o processo educativo em todas as suas instâncias.

\section{Referências}

Bauman, S. (2007). Vida líquida. São Paulo: Ed. Zahar.

Freire, P. (1984). A importância do ato de ler. São Paulo: Cortez.

Freire, P. (1997). A pedagogia da autonomia. Rio de Janeiro: Paz e Terra.

Freire, P. (2007). Educação como prática da liberdade. 30ª ed. São Paulo: Paz e Terra.

Grinspun, m. P. S. Z. e Azevedo, N. (2006). Subjetividade, contemporaneidade e Educação: Contribuição da Psicologia da Educação. 23a Reunião Anual da ANPED, 2000, Caxambu, MG, 2. Recuperado em 20 de janeiro de 2018, de www.anped.org.br/reuniões/23/textos/2036t.PDF.

Inbernón, F. (2010). Formação Continuada de Professores. Porto Alegre: Artmed.

Machado, J. A. (2013). A escola como espaço de formação continuada de professores: um estudo no contexto da Rede Municipal de Ensino de CANOAS-RS. Dissertação de Mestrado. Programa de Pós-Graduação em Educação/ Universidade La Salle.

Moriconi, G. M. (coord.). (2017). Formação continuada de professores: contribuições da literatura baseada em evidências. (Gabriela Miranda Moriconi, Claudia Leme Ferreira Davis, Gisela Lobo B. P. Tartuce, Marina Muniz Rossa Nunes, Yara Lúcia Esposito, Lara Elena Ramos Simielli, Nayana Cristina Gomes Teles). São Paulo: FCC. 59 p.; (Textos FCC: Relatórios técnicos, 52). Retrieved on 17 February 2018, from http://publicacoes.fcc.org.br/ojs/index.php/textosfcc/issue/viewIssue/340/169.

Nóvoa, A. (1999). Os professores na virada do milênio: do excesso dos discursos à pobreza das práticas. Revista Educação e Pesquisa, 25(1), 11-20. doi: 10.1590/S1517-97021999000100002

Nóvoa, A. (2004). Antonio Nóvoa em discurso directo: A solução pode estar no trabalho de pensar o trabalho. Revista número zero. São Paulo. 
Nóvoa, A. (2007). História de vida: perspectivas metodológicas. In.: A. Nóvoa (org.). Vida de Professores. $2^{\text {a }}$ ed. Porto: Porto Editora

Nóvoa, A. (2010). A escola o que é da escola. - Entrevista com António Nóvoa. Revista Escola Gestão Educacional. 8, 23-25.

Silva, G. F e Cabrera, F. A. (2013). Formação de professores: perspectivas docentes na ação educativa para a construção da cidadania intercultural. Revista Iberoamericana de Educación, 61(1), 1-13. Retrieved from https://rieoei.org/RIE/article/view/1280

Silva, G. F. e Machado, J. A. Saberes em diálogo: a construção de um programa de formação docente em uma rede municipal de ensino. Revista Iberoamericana de Educación / Revista Ibero-americana de Educação. 77(2), 95-114. Retrieved from https://rieoei.org/RIE/article/view/3161/3978

Tardif, M. (2002). Saberes docentes e formação profissional. Petrópolis: Editora Vozes.

Vaillant, D. (2016). Trabajo colaborativo y nuevos escenarios para el desarrollo professional docente. Docencia, 60, 6-13. Retrieved from https://ie.ort.edu.uy/innovaportal/file/48902/1/trabajo-colaborativo-y-nuevosescenarios-denise-vaillant.pdf

Data de recebimento: $21 / 06 / 2018$

Data da revisão: $27 / 12 / 2018$

Data do aceite: $29 / 12 / 2018$ 
